\title{
Leenders, T. 2016. Amphibians of Costa Rica: A field guide. Ítaca, Nueva York, Estados Unidos de América. Zona Tropical Publications
}

\author{
Víctor J. Acosta Chaves ${ }^{1,2}$ \\ 1. Instituto Internacional en Conservación y Manejo de Vida Silvestre, Universidad Nacional, Campus Omar Dengo, \\ Heredia, Costa Rica; victor2222@gmail.com \\ 2. Carrera de Turismo Ecológico, Recinto de Paraíso, Universidad de Costa Rica Sede Atlántico, Cartago, Costa Rica; \\ victor.acosta@ucr.ac.cr
}

Recibido 24-I-2017. Corregido 27-I-2017. Aceptado 31-I-2017.

\begin{abstract}
Book review directed to local tourism guides, naturalists and biologists on the new book "Amphibians of Costa Rica: A field guide” by Twan Leenders. Rev. Biol. Trop. 65 (2): 843-846. Epub 2017 June 01.
\end{abstract}

Key words: Amphibians of Costa Rica, book review, citizen scientist, field guide.

Probablemente Costa Rica está entre los países tropicales cuya riqueza de herpetofauna es mejor conocida al estar siendo estudiada desde hace más de un siglo y medio por científicos extranjeros y nacionales. La extensión territorial del país es de solo $51100 \mathrm{~km}^{2}$, pero se ubica entre los países con mayor diversidad de estos animales pues su gran riqueza de especies es proporcional a su amplia variedad de paisajes y topografía (Savage, 2002). El desarrollo del ecoturismo en el país lo ha posicionado como destino obligatorio para cualquier amante de la naturaleza, incluyendo a minuciosos observadores de su biodiversidad. Varios autores han creado libros y guías sobre los anfibios y reptiles, específicamente para Costa Rica, pero sin duda la titánica obra de Savage (2002) "The Amphibians and Reptiles of Costa Rica: a herpetofauna between Two Continents, between Two Seas" se convirtió en el texto por excelencia para cualquier estudioso contemporáneo de la herpetofauna del país y la región. Marcando un antes y un después, dicha obra maestra presentaba el mayor análisis comprensivo, fotográfico y bibliográfico sobre la diversidad de anfibios y reptiles de Costa Rica hace tres lustros. Casi paralelamente,
Leenders (2001) había presentado también su libro "A guide to Amphibians and Reptiles of Costa Rica", una guía de campo que tuvo bastante distribución en el país, cuyo precio accesible y difusión la hizo popular entre turistas, guías, naturalistas, estudiantes y biólogos. A pesar que el libro de Savage (2002) era incuestionablemente más completo y rico en contenido, la guía de Leenders (2001) resolvía el problema de no tener que cargar los más de $2.6 \mathrm{~kg}$ de peso del libro de Savage (2002) en condiciones de campo, facilitando el reconocimiento de las especies más conspicuas del país. Pero desde el lanzamiento del libro de Savage (2002) surgieron muchísimos cambios taxonómicos y se agregaron numerosas especies a la lista del país según Savage y Bolaños (2009) (actualizada hasta 2011 en la página web del Museo de Zoología de la Universidad de Costa Rica, MZUCR). Posteriormente Köhler (2011) lanzó "The Amphibians of Central America", pese a no tener tanta difusión en el país entre guías turísticos o aficionados, pues su contenido parecía dirigido a un público más especializado y familiarizado con el uso de claves dicotómicas. Otros autores como MuñozChacón y Johnston (2013) con su "Amphibians 
and Reptiles of Costa Rica: A Pocket Guide" de Zona Tropical crearon una guía de bolsillo más esquematizada y fácil de usar que la de Leenders (2001), no obstante con ciertas limitaciones de tamaño, errores de identificación y contenido tanto de anfibios como de reptiles (V. Acosta, observ.person).

$\mathrm{Si}$ bien para fines introductorios al tema habían suficientes fuentes bibliográficas relativamente fáciles de conseguir, hasta hace poco era complicado, para quienes debían profundizar más en la disciplina, ir al campo prescindiendo del libro de Savage (2002) o Köhler (2011), y de una serie de documentos que permitieran mantenerse actualizado con la taxonomía e identificación de los anfibios costarricenses. Pero tras 15 años desde de su primera guía, Leenders actualizó y mejoró su esfuerzo pionero con el tema de anfibios en su nuevo libro "Amphibians of Costa Rica: a Field Guide" publicado por la editorial Zona Tropical. Luego de donar algunas fotos de mi colección para este proyecto, quedé con gran curiosidad sobre el producto final, pero el resultado fue satisfactorio. Quise escribir esta reseña desde mi experiencia con turismo herpetológico y formador de futuros naturalistas, biólogos y guías turísticos, más que como un herpetólogo-científico puro; ese enfoque se lo dejo a otros colegas que sin duda harán revisiones técnicas más minuciosas.

Éste libro recuerda, en dimensiones y estructura, a la segunda edición de la popular guía de aves "The Birds of Costa Rica: A Field Guide" de Garrigues y Dean (2014), también de Zona Tropical, algo que me agradó como herpetólogo y observador de aves al estar familiarizado con ella, al igual que la mayoría de guías naturalistas del país.

La guía empieza explicando sus mapas y simbologías, las cuales resultan más informativos que los del mismo Savage (2002), así como las medidas morfométricas y estructuras morfológicas que hará referencia en el texto. Inmediatamente continúa con la tabla de contenido, un prefacio a cargo del renombrado conservacionista de anfibios Robin Moore y los respectivos agradecimientos. Seguidamente hay una introducción que deja claros los alcances de la obra, un apartado corto sobre geografía y clima, y una explicación sobre las ecoregiones del país. En la sección sobre clasificación y nombres científicos se justifica el uso de algunos nombres por lo complejo de las divisiones basadas fundamentalmente en caracteres moleculares, aunque no se indica si se sigue alguna fuente específica (e.g. Amphibian Species of The World). Se asume que esto disculparía el hecho que Strabomantinae se mantenga elevada a nivel de familia (Strabomantidae) y no como subfamilia de Craugastoridae (Padial et al., 2014). Por otro lado no se incluyeron en la guía los cambios del reciente artículo de Duellman et al. (2016) para Hylidae, que creó a la nueva familia Phyllomedusidae para las vistosas ranas de hojas como Agalychnis callidryas (especie portada del libro), probablemente por el traslape temporal en que ambos textos fueron publicados. Si los lectores quieren estar actualizados en la taxonomía de este grupo es recomendable consultar las fuentes anteriormente citadas. Sin embargo, comparto el punto de mantener la clasificación de familias de una forma más amigable y didáctica con el usuario para los fines de la guía. Cerrando la sección introductoria se toca una sección de recomendaciones para encontrar e identificar anfibios, el respeto hacia estos animales y cómo sería una correcta manipulación de los mismos; el autor dedica unos párrafos al contexto sobre el lamentable declive de poblaciones de anfibios en el país. Finaliza con un llamado a hacer ciencia ciudadana para incrementar el conocimiento y la exactitud de las distribuciones de las especies de anfibios costarricenses.

A continuación esta guía introduce cada Orden, Familia y Género de cecilias, salamandras y anuros con datos sobre su riqueza mundial y en el país, así como informaciones relevantes sobre su biología, para luego tratar con detalle cada especie, previa comparación gráfica de los géneros. Este documento ofrece la mayor lista de especies de anfibios costarricenses hasta el momento en un libro de esta naturaleza: 207. Incluye especies apenas recientemente descritas o conocidas del país. 
Aunque probablemente la revisión física de la colección del MZUCR hubiese agregado al menos una especie adicional a las presentadas en la obra (V. Acosta, observ.person), es lógico que el autor usase solo las especies que aparecen en la última actualización de la lista de Savage y Bolaños (2009) y manuscritos recientemente publicados; parece que es conveniente que el MZUCR actualice su lista oficial.

Cada ficha de especie presenta el nombre científico y común en inglés, su estado de riesgo según "The IUCN Red List of Threatened Species", un resumen con sus medidas morfométricas y características taxonómicas, un mapa con su distribución histórica (cuando aplica) y actual por ecoregión, una descripción detallada de características que facilitarían su identificación apoyándose en una o varias imágenes de alta calidad (para la mayoría de especies), y finalmente, una sección de especies similares, también comparando, con texto e imágenes, la especie tratada contra dichas especies. A mi parecer el trabajo de fotografía y diagramación es exquisito, colocando a la mayoría de especies sobre un fondo blanco. Esto permite el aprovechamiento del espacio y resalta las características propias de los animales, algo que han demostrado otras obras como la magnífica "The Amphibians and Reptiles of Mindo: Life in the Cloudforest" de Arteaga et al. (2013). Otras imágenes de huevos, estadios larvales, juveniles, morfos diurnos o nocturnos, entre otras cosas enriquecen sustancialmente las fichas. Todo este esfuerzo resume de manera eficiente la información disponible y actualizada para cada especie. A mi parecer, esta guía además profundiza en un grupo que otros autores no han dado tanta prioridad a la hora de ilustrar para facilitar su identificación, y del que se conoce poco, como son las salamandras neotropicales sin pulmones (Phlethodontidae).

Si bien la identificación exacta de herpetofauna generalmente se ha hecho gracias a claves dicotómicas como las de Savage (2002) o Köhler (2011), estas claves funcionan bien para muchos organismos (e.g. Phletodontidae o Terrarana) sólo si se tienen organismos preservados para comparar a la mano, se conoce perfectamente el nombre de muchas estructuras morfológicas o tras abundantes observaciones propias de las especies, siendo limitada su aplicabilidad en el campo para ciertos usuarios sin formación estricta de zoólogos. Pero la forma en que este nuevo libro detalla a la especies y las compara, facilita su correcta, o al menos cercana, identificación a nivel de género y especie sin requerir de demasiados recursos a la mano. No obstante, no se puede descartar que en algunos pocos casos siempre se tenga que recurrir a las claves dicotómicas o a literatura clásica para vislumbrar la identidad de ciertas especies polimórficas o crípticas.

El autor finaliza con un glosario, bibliografía recomendada por el autor, créditos para quienes donaron fotografías, un índice y el mapa físico de Costa Rica. Probablemente mi principal queja para ésta u otras guías populares de vertebrados en Costa Rica que ha publicado Zona Tropical y otras editoriales, es que, al menos por ahora, sólo se encuentran en lenguaje inglés. Esto dificultaría aún más la generación de ciencia ciudadana, aunque afortunadamente una gran mayoría de personas que trabajan con turismo o ciencia en el país, tendrán una noción básica o avanzada del inglés. Lo anterior no le quita mérito al inmenso trabajo de Leenders para crear esta pequeña joya; los lectores deben saber que todo libro de esta calidad es sólo producto de muchísimas incursiones en el campo y tiempo invertido fotografiando, leyendo, analizando datos, escribiendo y editando; y por supuesto la información generada gracias a la recolecta de individuos por naturalistas, científicos y museos de Costa Rica y el mundo.

Creo que fue acertada la decisión del autor de separar anfibios y reptiles para este proyecto, pues le permitió conseguir el equilibrio tamaño-contenido en su obra; considero incluso que será un modelo a seguir para futuros proyectos en zonas Neotropicales similares. Esta nueva guía de campo no peca por caer en la rigidez de un texto demasiado especializado cual catálogo de especies, pero tampoco es escueta o poco novedosa como otras guías recientes sobre herpetofauna de Costa Rica (e.g. "A field 
guide to the Snakes of Costa Rica" de Chimaira según lo justificó Barrio-Amorós (2014)). Concuerdo plenamente con el Dr. Moore en el hecho de que ésta guía se convirtió actualmente, en la mejor herramienta de campo para descubrir el fascinante mundo de los anfibios costarricenses; por supuesto, sin prescindir de la compañía de expertos locales y foráneos. Queda claro que este producto dejará satisfechos a aficionados y profesionales en la disciplina; sin duda "Amphibians of Costa Rica: a Field Guide" será una pieza infaltable en la biblioteca de cualquier naturalista interesado en la biodiversidad costarricense.

\section{REFERENCIAS}

Arteaga, A., Bustamante, L., \& Guayasamín, J. M. (2013). The Amphibians and Reptiles of Mindo: Life in the Cloud Forest. Quito: Universidad Tecnológica Indoamérica.

Barrio-Amorós, C. L. (2014). Book Review: A Field Guide to the Snakes of Costa Rica. Herpetological Review, $45,525-528$.
Duellman, W. E., Marion, A. B., \& Hedges, S. B. (2016). Phylogenetics, classification, and biogeography of the treefrogs (Amphibia: Anura: Arboranae). Zoota$x a, 4104,1-109$.

Garrigues, R., \& Dean, R. (2014). The birds of Costa Rica: A field Guide. Nueva York: Zona Tropical Publications.

Köhler, G. (2011). Amphibians of Central America. Offenbach: Herpeton.

Leenders, T. (2001). A guide to amphibians and reptiles of Costa Rica. Nueva York: Zona Tropical Publications.

Muñoz-Chacón, F., \& Johnston, R. D. (2013). Amphibians and Reptiles of Costa Rica: A Pocket Guide. Nueva York: Zona Tropical Publications.

Padial, J. M., Grant, T., \& Frost, D. R. (2014). Molecular systematics of terraranas (Anura: Brachycephaloidea) with an assessment of the effects of alignment and optimality criteria. Zootaxa, 3825, 1-132.

Savage, J. M. (2002). The Amphibians and Reptiles of Costa Rica: A Herpetofauna between Two Continents, between Two Seas. Chicago: University of Chicago Press.

Savage, J. M., \& Bolaños, F. (2009). A checklist of the amphibians and reptiles of Costa Rica: additions and nomenclatural revisions. Zootaxa, 2005, 1-23. 